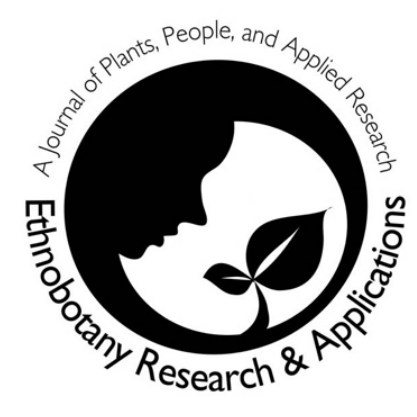

\title{
An ethnobotanical study of traditional medicinal plants used for human ailments in Yem ethnic group, south Ethiopia
}

Gideon Woldemariam, Sebsebe Demissew and Zemede Asfaw

\author{
Correspondence \\ Gideon Woldemariam ${ }^{1 *}$, Sebsebe Demissew² and Zemede Asfaw ${ }^{2}$ \\ ${ }^{1}$ Wolaita Sodo University Department of Biology P.O. Box 138 \\ ${ }^{2}$ Addis Ababa University, Department of Plant Biology \& Biodiversity Management P.O. Box 3434 \\ *Corresponding Author: gideongw2016@gmail.com
}

Ethnobotany Research \& Applications 22:08 (2021)

\section{Research}

\begin{abstract}
Background: Medicinal plants (MPs) have been widely used traditionally for strengthening the health care among communities of low-income countries including Ethiopia. The Yem ethnic group in Ethiopia traditionally utilize MPs for treating human ailments since ancient times. However, MPs and the associated traditional knowledge are under erosion due to human-induced and natural factors. Therefore, documenting the plant biodiversity along with the associated indigenous knowledge is an urgent task for conservation.
\end{abstract}

Methods: This study was conducted between 2013 and 2016 with the objective of documenting MPs used for treating human ailments. Ethnobotanical data were collected using semi-structured interviews and guided transect walks. The data were collected from 69 informants that were selected by stratified random sampling and purposive sampling. Data were analyzed using paired ranking (PR), Informant consensus factor (ICF), Fidelity Level (FL (\%)) and Direct Matrix Ranking (DMR).

Results: About 213 plant species that are used for treating 117 human ailments were recorded. Gastrointestinal \& Visceral organs ailments scored the highest ICF value of 0.82 . Analysis of FL revealed that species such as Haplocarpha rueppellii, Carduus schimperi and Inula confertiflora had a 100\% fidelity, Maesa lanceolata $80 \%$ and Rumex abyssinicus 75\% fidelity. Multipurpose medicinal species such as Cordia africana, Juniperus procera and Podocarpus falcatus were species locally threatened by use pressure.

Conclusion: The Yem ethnic group has rich traditional knowledge of utilizing diverse plant species for maintaining human health care. Conducting phytochemical screening and clinical trials of the species with high fidelity is suggested for their efficacy, safety, and standard uses.

Keywords: Asteraceae, gender, herbal experts, maceration, regression model, Rumex abyssinicus, Yemisa

\section{Background}

Medicinal plants have been used in healthcare since ancient times (Sofowora et al. 2013). They have been widely used for strengthening the health care systems in low-income countries (Ahlberg 2017) and contributed for 
manufacturing of $20 \%$ of drugs in modern medicine (Fabricant \& Farnsworth 2001, Farnsworth \& Soejarto 1991). People of Ethiopia in the SubSaharan Africa are dependent on natural flora for health care and earning livelihood (FAO 2010, UNESCO 2015). The diverse ethnicities of Ethiopia have millennia old ethnobotanical knowledge beliefs, and practices about plant species growing in different vegetation and land use types. Traditional medicine that mainly employs MPs has been normative and integral part of health care system in the country (Deribe et al. 2006, Levine 1974, Pankhurst 2001). Estimates show that about $80 \%$ of human population health care in the country is based on traditional MPs (Abebe \& Ayehu 1993, WHO 2002). The ethnicities of the country are estimated to use about a third of the country's plant families in traditional medicine for maintaining their health care (Tadesse \& Demissew 1992). Yem people are one of the ethnic groups of Ethiopia who are inhabitants of Dry Afromontane Region in southern part of the country and have a deep-rooted and ancient traditional knowledge of managing human ailments and health conditions using plant biodiversity. Even though the mainstream biomedical system showed better coverage than before, Yem people still use plants and consult local herbal experts for several human ailments and health conditions due to their accessibility, millennia old experimentation on the efficacy of traditional herbal medicines that led to cultural trust in them. However, the MPs and the associated knowledge are being seriously in danger due to deforestation for agricultural expansion, firewood and charcoal extraction, environmental degradation, modernization, and climate change that could ultimately undermine the primary healthcare options. Thus, urgent ethnobotanical studies and subsequent conservation measures are needed to restore MPs and the associated knowledge from further loss. The objectives of this study were to document of MPs and associated knowledge of human ailments and analyze effects socioeconomic variables on mpk among Yem ethnic group.

\section{Materials and Methods}

\section{Description of the study area}

Yem people live in Yem Special District in the north-western apex of Southern Regional State within coordinates of $7^{\circ} 37^{\prime} \mathrm{N}-8^{\circ} 02^{\prime} \mathrm{N}$ and $37^{\circ} 40^{\prime} \mathrm{E}-37^{\circ} 61^{\prime} \mathrm{E}$ (Figure 1). Four subdistricts of the Special District were sampled for this study, namely, Gorumina Hanigeri, Kesheli, Shemona Metelo and Saja Lafiten. Yem people speak its own distinct 'Yemisa' that is categorized in Omotic language group (Negash 2005). According to CSA (2007), the total population of Yem was estimated to be 80,647 , of which $50.3 \%$ were males and $49.7 \%$ females and the population density was 111.30 persons per sq. $\mathrm{km}$. About $71.24 \%$ of the population was said to practice Orthodox Christianity, $25.14 \%$ Muslim and 3.48\% Protestants (CSA 2007). The ethnic group practices enset-based subsistence crop cultivation and livestock rearing (YDAO 2016). Metrological data received from Deri station in Yem showed that high rainfall was received between May to September whereas low rainfall recorded from November to February reaching the lowest of $25 \mathrm{~mm}$ in December within 13 years (2000-2012) (NMSA 2014), Similarly, the highest mean annual temperature was $21{ }^{\circ} \mathrm{C}$ recorded in May while the lowest mean annual temperature within 13 years was $7{ }^{\circ} \mathrm{C}$ recorded in December (NMSA 2014).

\section{Data Collection}

Ethnobotanical Data

For the ethnobotanical investigation and vegetation survey, four subdistricts shown in the map were selected purposively based on agroecological (climatic) barrier, one from highland (i.e. Kesheli), two from middle land (Gorumina Hanigari and Shemona Metelo), and one from lowland (Saja Laften) as used by Cadena-González et al. (2013). Ethnobotanical data were collected using semi-structured interviews and guided transect walks following Martin (1995). Ethnobotanical information was gathered from 69 informants of the four subdistricts. Forty-seven (68\%) of the informants were general (lay) informants, who were selected using Stratified Random Sampling (SRS) and 22 (32\%) were key (expert) informants that were selected purposively from the four subdistricts following (Martin 1995). Semi-structured interviews were conducted in 'Yemisa' (in three of the sub districts) and 'Oromiffa' (Oromo language) in Saja Laften, and then translated by the help of guides. The interviews were conducted using 'interview guide' that was prepared a priori as suggested by Martin (1995) and the responses were recorded in hard copy of the guide per informant. Oral consent of informants was sought before interview administration.

Identification of the plant species specimens were made by the investigator in the National Herbarium of Ethiopia (ETH) using the published volumes Flora of Ethiopia and Eritrea Volumes 1- 8 (Hedberg et al. 2009). Voucher specimens were stored in the ETH. 


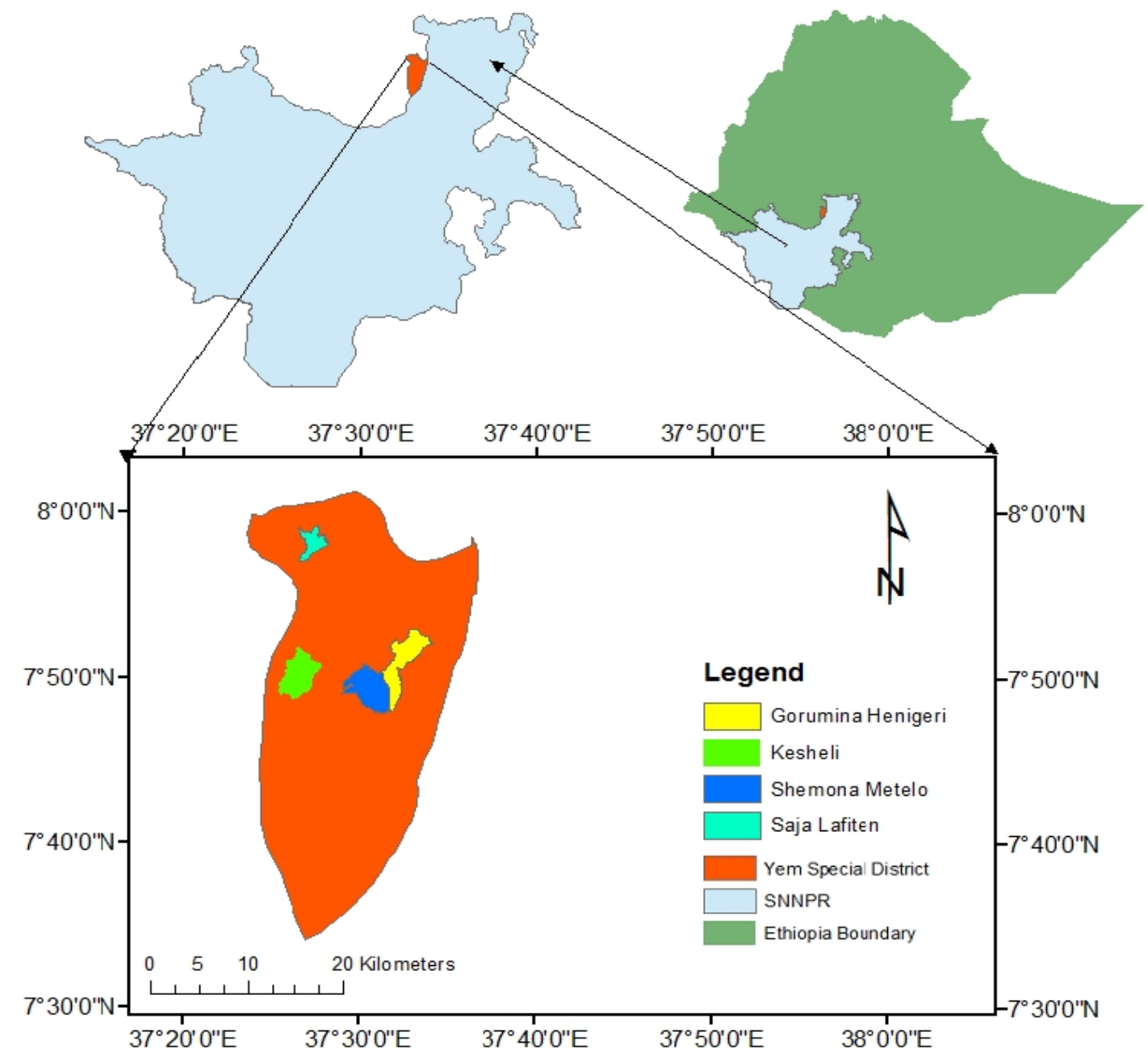

Figure 1. Location map of Yem Special District and subdistricts under study in Ethiopia

\section{Analysis of Data}

Ethnobotanical data were analyzed using quantitative tools listed below:

Paired ranking

Paired comparison of highly cited medicinal plants was done with randomly selected key informants following Martin (1995). Then, the scores of each species were summed up and ranked based on the preference of the key informants against a given disease.

\section{Informant Consensus Factor (ICF)}

The ICF of MPs which had highest citations for treating human ailments were calculated to evaluate the level of homogeneity of information provided by different informants following Trotter and Logan (1986). The index was calculated as the number of use citations in each category minus the number of species used divided by the number of use citations in each category minus one. The formula of the index is:

$$
\mathrm{ICF}=\frac{\mathrm{Nur}-\mathrm{Nt}}{\mathrm{Nur}-1}
$$

where, Nur = number of use reports from informants for a particular plant-use category; Nt $=$ number of taxa or species that are used for that plant use category for all informants. For the ICF analysis, ailments were grouped into nine categories as suggested by Cook (1995). The categories of ailments were: blood vascular \& infectious, dermatological, gastrointestinal \& visceral organs, miscellaneous, musculoskeletal, respiratory system, psychospiritual \& cultural, reproductive \& urogenital, and sensorial ailments and headache. Miscellaneous ailments are ailments whose sign and symptoms and specific body part could not be clearly stated. 
Fidelity Level, FL (\%) medicinal species

Fidelity Level (FL\%) of medicinal species used for human ailments was calculated to identify species with highest healing potential. This index is calculated as the ratio between the number of informants who suggested the use of a species for the same major purpose $\left(\mathrm{I}_{\mathrm{p}}\right)$ and the total number of informants who mentioned the plant for any use (lu) (Friedman et al. 1986). The formula for fidelity level (FL) is:

$$
\mathrm{FL}=\frac{\mathrm{Ip}}{\mathrm{Iu}}
$$

where $\mathrm{FL}=$ Fidelity Level $(\mathrm{FL} \%), I_{p}=$ the number of informants who suggested the use of a species for the same major purpose; lu = the total number of informants who mentioned the plant for any use.

\section{Direct Matrix Ranking}

The exercise of Direct Matrix Ranking (DMR) of multipurpose MPs used for human ailments was performed separately with randomly selected 10 key informants to find out the threatened species by use pressure following Martin \{1995).

\section{Jaccard's Coefficient of Similarity (JCS)}

The similarity of medicinal species used by the Yem were compared with ethnomedicinal investigations in other ethnic groups in Ethiopia was done using JCS following Kent and Cocker (1992).

$$
\mathrm{JCS}=\frac{\mathrm{c}}{\mathrm{a}+\mathrm{b}+\mathrm{c}}
$$

where $\mathrm{a}=$ no. of species in site $\mathrm{A}$ only, $\mathrm{b}=$ no. of species in Site B only, and $\mathrm{c}=$ no. of species in both sites.

\section{Statistical Analyses of Data}

Data were entered, organized, and analyzed in MS excel spreadsheet (Microsoft 2007). The ethnobotanical data were analyzed using MS excel and multiple regression analysis was used for testing socioeconomic variables that are significant predictors of medicinal knowledge of informants in Statistical Package for Social Sciences (SPSS) version 20 (IBM 2011).

\section{Results}

\section{Ethnobotanical Data}

Ailments freelisted, diversity, life forms and habitats of medicinal species used for treatment

In total, 117 human ailments and health conditions were freelisted by informants (Appendix 1) that were treated by 213 medicinal plant species, which were classified in 184 genera and 80 families (Appendix 2). Among ailments freelisted, abdominal pain was the highest cited, 130 (7.59\%) followed by acute febrile illness 129 (7.53\%) and foot swelling disease ('danifurutu'/'awachifebe?u') 69 (4.03\%).

Herbaceous life forms were the most cited for treating ailments i.e. 97 (45\%) followed by shrubs 54 (25\%) and trees $33(15 \%)$. About 56 (70\%) of the families treated a single ailment and health condition while 24 (30\%) of them treated more than a single ailment. Those families which were used to treat multiple human ailments include Asteraceae, Alliaceae, Euphorbiaceae, Fabaceae, Lamiaceae, Rutaceae and Solanaceae. Asteraceae was the medicinal species richest family with 26 taxa followed by Lamiaceae 18, Fabaceae 19 and Euphorbiaceae 8. About 177 (83\%) of medicinal species are known to be harvested from wild while 28 (15\%) of them are cultivated. The medicinal species are known to be distributed in 13 different habitats (Figure 2). Forest constituted highest of 68 (32\%) species followed by home garden 30 (14\%) and living fence and fallow 24 (11\%) each.

\section{The number of taxa used per ailment}

The findings showed that about 117 (55\%) species were used to treat a single ailment while 96 (45\%) of them were used to treat more than a single ailment. Among those species which treated multiple ailments, Rumex abyssinica was applied to treat as high as 9 ailments followed by Artemisia abyssinica and Phytolacca dodecandra each treated 6 ailments, Allium sativum and Clematis longicauda each treated 5 ailments (Appendix 2). For the rest of taxa, 3 species treated 4 ailments; 21 species treated 3 ailments; and 54 species 2 ailments. Vice-versa, the summary of ailments treated by number of taxa showed that 67 (57\%) ailments were treated by a single species; 17 ailments by 2 taxa; 15 ailments by 4 taxa; 7 ailments by 5 taxa; 5 ailments by 6 taxa; 1 by 7 taxa; 3 ailments by 8 taxa, 2 ailments 
by 9 taxa; 2 ailments by 11 taxa, 1 ailment by 13 taxa, 3 ailments by 14 taxa and a single ailment i.e 'mich' by 17 taxa.

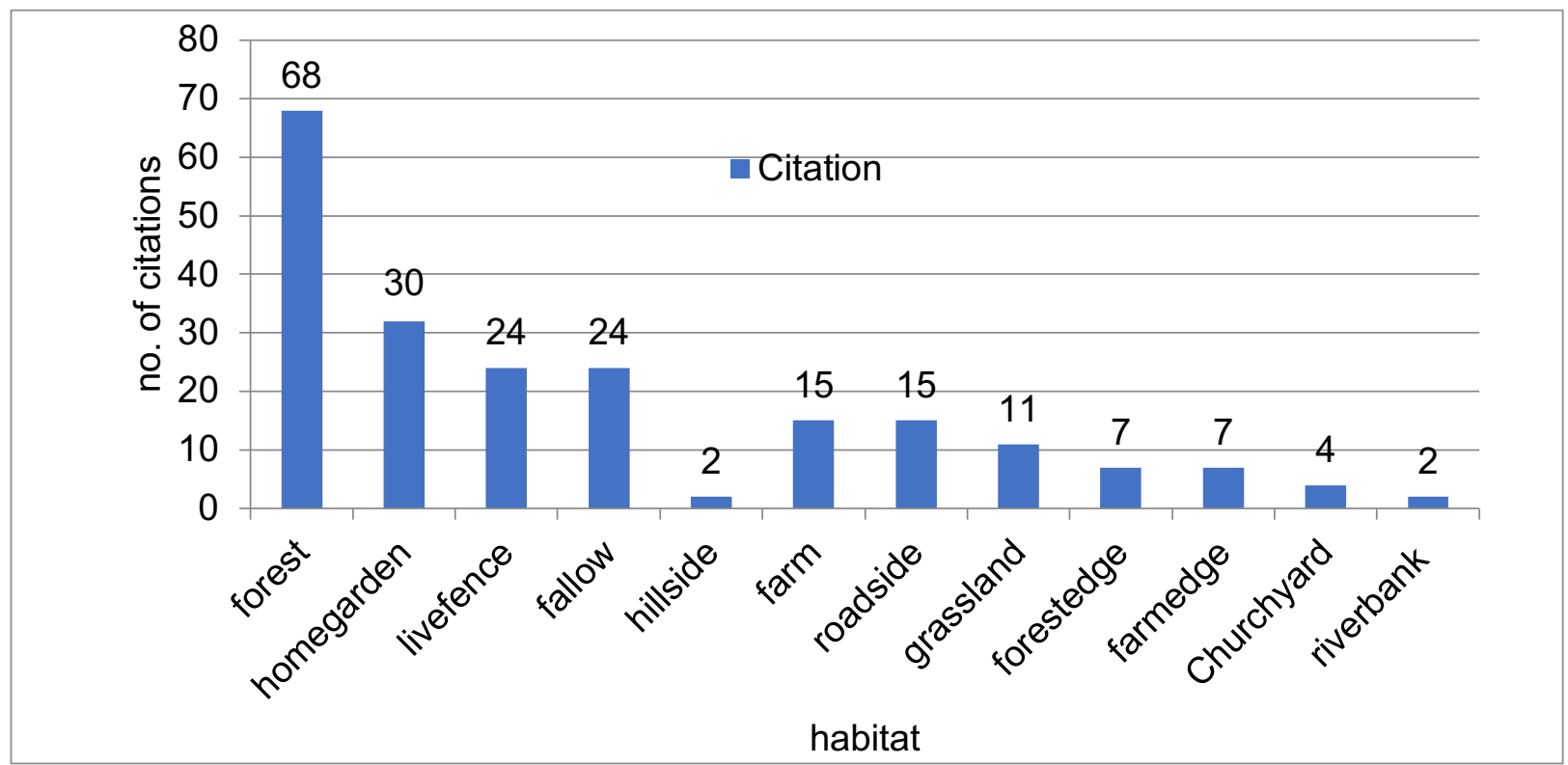

Figure 2. Habitat of MPs used for human ailments

Parts, methods of preparation, routes, and mode of application of medicinal plants

The results showed that leaf was the highest cited part for 197 (45\%) preparations followed by root 83 (19\%). About 10 different methods of preparation of plant remedies were reported among which maceration was the most used method with 201 (46\%) remedies followed by decoction 85 (19\%) and infusion 64 (15\%) (Figure 3). About 296 (68\%) remedies were taken via oral route followed by 71 (16\%) dermal and $20(5 \%)$ nasal. Drink was the most cited mode of application for the highest of 310 (71\%) remedies followed by paint $26(6 \%)$, inhale $25(6 \%)$ and chew \& swallow 20 (5\%).

\section{Informant Consensus Factor (ICF)}

The results of ICF calculated depicted largest ICF value of 0.82 (Table 1) for Gastrointestinal \& Visceral organs ailments category (GIV) which were treated by 91 species and had 506 use reports. There were 15 ailments under this category, the prominent ones being abdominal pain, hepatitis, diarrhea and taeniasis. The next category with highest ICF value was MiSc (ICF 0.81). Specific ailments and conditions treated under this category among others were 'mich', sudden ailment, febrile illness, and foot swelling ailment /'awachife'be'u'/'danifurutu'/. The third category with the next highest ICF was RS $(I C F=0.80)$. The category with the least ICF was BVI ailments scoring 0.67 (but treated by as high as 71 species).

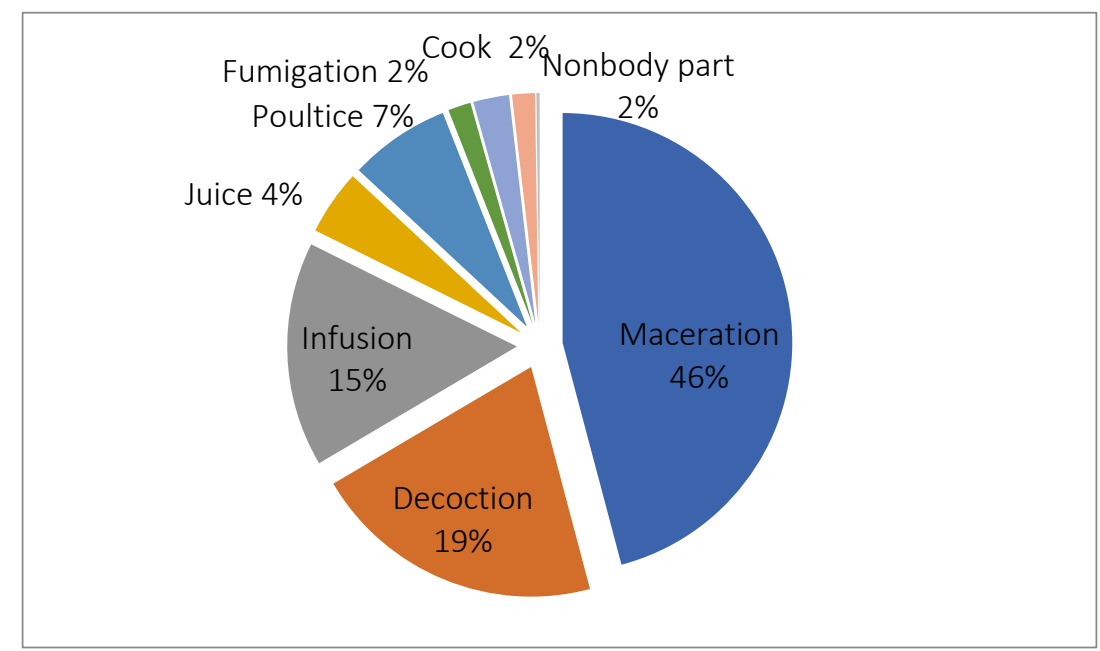

Figure 3. Methods of remedy preparation 
Table 1. ICF values of MPs for human ailments

\begin{tabular}{lccc}
\hline Category & UR & Spp. & ICF \\
\hline BVI & 211 & 70 & 0.67 \\
DR & 207 & 59 & 0.72 \\
GIV & 506 & 91 & 0.82 \\
MiSc & 277 & 54 & 0.81 \\
MSK & 114 & 31 & 0.73 \\
PS & 67 & 18 & 0.74 \\
RUG & 97 & 32 & 0.68 \\
RS & 143 & 30 & 0.80 \\
SH & 106 & 28 & 0.74 \\
\hline
\end{tabular}

$U R=$ no. of use reports, spp.= \# of species used for treating ailments, BVI = Blood Vascular \& Infectious, DR = Dermatological, GIV = Gastrointestinal \& Visceral organs, MiSc = Miscellaneous, MSK = Musculoskeletal, RS = Respiratory System, PS = Psychospiritual \& cultural, RUG = Reproductive \& Urogenital, $\mathrm{SH}=$ Sensorial ailments \& Headache)

Fidelity level, FL (\%) of selected medicinal species

Species that scored large FL values include Haplocarpha rueppellii (used for treating abdominal pain), Carduus schimperi (used for acute febrile illness) and Inula confortiflora (used for sudden ailment) each 100\%, Maesa lanceolata (used for abdominal worms) $80 \%$, Rumex abyssinicus (used for hepatitis) $75 \%$, Verbena officinalis (used for child diarrhea) 65\%, Brucea antidysenterica (for abdominal pain \& diarrhea) 65\% and Hagenia abyssinica (used for taeniasis) $60 \%$ (Table 2).

Table 2. FL (\%) of selected species with large values

\begin{tabular}{llccc}
\hline Species & Ailment treated & Ip & lu & FL(\%) \\
\hline Haplocarpha rueppellii & abdominal pain & 40 & 40 & 100 \\
Carduus schimperi & acute febrile illness & 25 & 25 & 100 \\
Inula confertiflora & sudden ailment & 17 & 17 & 100 \\
Maesa lanceolata & abdominal worms & 13 & 16 & 80 \\
Embelia schimperi & abdominal worms & 12 & 16 & 75 \\
Rumex abyssinicus & hepatitis & 24 & 32 & 75 \\
Verbena officinalis & child diarrhea & 12 & 18 & 65 \\
Brucea antidysentrica & sudden abdominal pain & 9 & 14 & 64 \\
Hagenia abyssinica & taeniasis & 17 & 28 & 60 \\
\hline
\end{tabular}

\section{Average Direct Matrix Ranking (ADMR)}

The analysis of ADMR revealed that Cordia africana, Juniperus procera and Podocarpus falcatus were species locally threatened multipurpose medicinal species ranking between 1-3, respectively, by activities of fuel wood, construction, and lumbering (Table 3).

Table 3. Average Direct Matrix Ranking of 10 multipurpose medicinal species

\begin{tabular}{lllllllll}
\hline Species & \multicolumn{3}{l}{ Use category } & \multicolumn{3}{c}{ T } & \multirow{2}{*}{ R } \\
\cline { 2 - 7 } & 5 & $\mathrm{~B}$ & $\mathrm{C}$ & $\mathrm{D}$ & $\mathrm{E}$ & $\mathrm{F}$ & & \\
Cordia africana & & 5 & 5 & 3 & 5 & 5 & 28 & 1 \\
Croton macrostachyus & 3 & 1 & 3 & 2 & 3 & 5 & 17 & 9 \\
Erythrina brucei & 1 & 1 & 2 & 2 & 3 & 2 & 11 & 11 \\
Gardenia ternifolia & 3 & 3 & 5 & 5 & 3 & 2 & 21 & 6 \\
Hagenia abyssinica & 3 & 2 & 5 & 4 & 4 & 4 & 22 & 4 \\
Hypericum quartinianum & 2 & 2 & 5 & 4 & 3 & 1 & 17 & 9 \\
Juniperus procera & 3 & 4 & 5 & 3 & 5 & 5 & 25 & 2 \\
Olea europaea subsp. cuspidata & 3 & 3 & 4 & 3 & 3 & 2 & 18 & 8 \\
Olinia rochetiana & 1 & 3 & 5 & 4 & 4 & 3 & 20 & 7 \\
Podocarpus falcatus & 5 & 4 & 5 & 2 & 5 & 5 & 26 & 3 \\
Total & 34 & 34 & 52 & 39 & 46 & 39 & & \\
Rank & 5 & 5 & 1 & 3 & 2 & 3 & & \\
\hline
\end{tabular}

$A=$ furniture, farming \& household tools, $B=$ fodder, $C=$ fuel wood, $D=$ charcoal, $E=$ construction, $F=$ lumber, $\mathrm{R}=$ Rank, $\mathrm{T}=$ total) 
Indigenous medicinal plant knowledge (mpk) and socio-economic variables

The proportions of informants based on socio-economic variables (predictor variables) are given in Table 4.

Table 4. Proportion of informants by socioeconomic variables

\begin{tabular}{llll}
\hline Variable & Category & no. & $\%$ \\
\hline Gender & male & 38 & 55 \\
Age & female & 31 & 45 \\
& young (18-35) & 12 & 17 \\
\multirow{4}{*}{ Religion } & middle (36-50) & 19 & 28 \\
\multirow{3}{*}{ Education } & old (>50) & 38 & 55 \\
& Orthodox & 51 & 74 \\
Informant proficiency & Muslim & 16 & 23 \\
& non-educated & 36 & 52 \\
& General informant & 47 & 68 \\
& high school \& above & 5 & 7 \\
& Key informant & 22 & 32 \\
\hline
\end{tabular}

In the analysis of mpk among informants using multiple linear regression, the predictor variables were age, education, gender, informant proficiency and religion while the dependent variable was the number of medicinal plants.

The regression model showed that $31.10 \%$ of the variance was explained by the model with a modest correlation of 0.56 between the outcome and predictor variables (Table 5). The model was a significant predictor of $\mathrm{mpk}, \mathrm{F}$ $(5,63)=5.69, p<0.001$ (Table 6). Two of the variables, namely, gender $(B=-6.13, p=0.025)$ and informant proficiency $(B=10.08, p<0.001)$ significantly contributed to the model while age $(B=-0.28, p=0.88)$, religion ( $B$ $=-4.50, p=0.09)$ and education $(B=-0.36, p=0.87)$ did not (Table 7). Based on the model, there was a modest positive correlation between informant proficiency and mpk, $r=.46(p<0.001)$, and a modest negative correlation between gender and $\mathrm{mpk}, \mathrm{r}=-.36(\mathrm{p}=0.001)$.

The regression model was equated as:

$m p k=21.24-6.13^{\star}$ gender $-0.28^{\star}$ age $-4.50^{\star}$ religion $-0.36^{\star}$ education $+10.07^{\star}$ informant proficiency .

Table 5. Model Summary of regression

\begin{tabular}{lllll}
\hline Model & $\mathrm{R}$ & $\mathrm{R}$ Square & Adjusted R Square & Std. Error of the Estimate \\
1 & $.56^{\mathrm{a}}$ & .31 & .26 & 10.26 \\
a. Predictors: (Constant), informant, religion, education, gender, age & \\
\hline
\end{tabular}

Table 6. ANOVA of Regression model

\begin{tabular}{llllll}
\hline ANOVA $^{\text {a }}$ & & & & \\
Model & Sum of Squares & df & Mean Square & F & Sig. \\
1 Regression & 2997.071 & 5 & 599.41 & 5.69 & $.000^{b}$ \\
$\quad$ Residual & 6630.17 & 63 & 105.24 & & \\
$\quad$ Total & 9627.25 & 68 & & & \\
$\begin{array}{l}\text { a. Dependent Variable: } \mathrm{mpk} \\
\text { b. Predictors: (Constant), informant, religion, education, gender, age }\end{array}$ & & \\
\hline
\end{tabular}

\section{Similarity of Yem MPs with other ethnic groups across Ethiopia}

Comparison made with the MPs for human use reported from 14 cultures in Ethiopia showed the highest similarity of $37 \%$ traditional MPs used in Sheko ethnic group and West Shoa Oromo people (Table 8). The next closer similarity was with KembataTembaro ethnic group 31\% and Dawuro 26\%. The MPs by Gonder Amhara, Ankober Amhara and Tigre also had closer similarity with that of Yem. The least similarity of $5 \%$ was observed with Harer Oromo. 
Table 7. Regression model coefficients

\begin{tabular}{|c|c|c|c|c|c|}
\hline \multirow[t]{2}{*}{ Model 1} & \multicolumn{2}{|c|}{ Unstandardized Coefficients } & \multirow{2}{*}{$\begin{array}{l}\text { Standardized Coefficients } \\
\text { Beta }\end{array}$} & \multirow[t]{2}{*}{$\mathrm{t}$} & \multirow[t]{2}{*}{ Sig. } \\
\hline & B & Std. Error & & & \\
\hline (Constant) & 21.24 & 10.58 & & 2.01 & .049 \\
\hline gender & -6.13 & 2.67 & -.25 & -2.29 & .025 \\
\hline age & -.28 & 1.79 & -.02 & -.16 & .877 \\
\hline religion & -4.50 & 2.64 & -.18 & -1.70 & .094 \\
\hline education & -.36 & 2.23 & -.02 & -.16 & .871 \\
\hline $\begin{array}{l}\text { Informant proficiency } \\
\text { a. Dependent Variable: mpk }\end{array}$ & 10.08 & 2.76 & .39 & 3.65 & .001 \\
\hline
\end{tabular}

Table 8. Jaccard Coefficient of Similarity (JCS) of Yem mps with other reports

\begin{tabular}{llll}
\hline Ethnic group & no. of MPs & JCS & Author/s \\
Gera Oromo & 63 & 0.15 & Gonfa et al. (2020) \\
Sheko & 256 & 0.37 & Kassa et al. (2020) \\
Tigre & 173 & 0.21 & Kidane et al. (2017) \\
Harer Oromo & 83 & 0.05 & Belayneh and Bussa (2014) \\
Gonder Amhara & 135 & 0.23 & Chekole (2017) \\
Dawuro & 168 & 0.26 & Agize et al. (2013) \\
Ankober Amhara & 135 & 0.22 & Lulekal et al. (2013) \\
KembataTembaro & 145 & 0.31 & Maryo et al. (2015) \\
Berebere Bale Oromo & 70 & 0.13 & Tolossa and Megersa (2018) \\
West Shoa Oromo & 172 & 0.37 & Regassa (2016) \\
Bale National Park & 101 & 0.10 & Yineger et al. (2008) \\
Debark Amhara & 88 & 0.21 & Abebe et al. (2011) \\
Goma Oromo & 92 & 0.26 & Etana et al. (2010) \\
Yem & 213 & & Current study \\
\hline
\end{tabular}

\section{Discussion}

Diversity, abundance, and habit of MPs reported for human ailments

The findings showed that the Yem have rich traditional knowledge of MPs for treating several human ailments and conditions side by side with the biomedical health system. This rich traditional knowledge might have been acquired through long experiences and trial \&error by forebears of the ethnic group leading to discovery of efficacious taxa used by the society. Moreover, the accessibility of MPs, cultural acceptance of natural remedies from plants, and the cost of the biomedical health care are drivers for extensive use of plant remedies for human primary health care. Similar to our finding, reports by Giday (2007) in Bench, Meinit and Sheko, Lulekal et al. (2013) in Ankober Amhara, Agize et al. (2013) in Dawuro, Maryo et al. (2015) in Kembata Tembaro, Regassa (2016) in West Shoa Oromo ethnic groups in Ethiopia, and in overseas, Casagrande (2002) in Tzeltal Maya, Hong et al. (2015) in Maonan people China and Reimers et al. (2018) in Zacatecas state Mexico, have also reported traditional use of plants for treating human ailments.

Few medicinal families such as Asteraceae, Alliaceae, Euphorbiaceae, Fabaceae, Lamiaceae, Rutaceae and Solanaceae were found to treat more than a single ailment, which might be attributed to the popularity of these families among the community for treating multiple of ailments. Among these families, Asteraceae was a family used to treat the highest number of health problems, which might be attributed to big number of medicinal taxa it contains. Reports indicate that a big number of taxa of this family are proven to possess rich secondary metabolites such as steroids, terpenes and alkaloids which are used as anti-inflammatory, analgesic anti-pyretic and antioxidant agents that act against ailments in support with the traditional use of its taxa for human remedies (Desmarchelier \& Witting-Schaus 2000, Ross 2005, Sílvia et al. 2015). The dominance of taxa of Asteraceae for human remedies in current finding agrees with other works in Ethiopia such that of Giday (2007), Maryo et al. (2015), Regassa (2016), and in overseas Hassan et al. (2017) in Pakistan, Hong et al. (2015) in China, Moerman et al. (1999) and Reimers et al. (2018) in Zacatecas state, Mexico.

Number of ailments treated, life forms, sources and habitat of MPs

The use of multiple therapeutic species for a single ailment in our finding was based on two folds of explanations. First, use of different species for a single human ailment might be in that informant of different subdistricts use 
different species for the same case based on the availability of therapeutic species and individual difference in knowledge. Secondly, most healers interviewed use concoctions for several ailments with a thought that the concoction better acts synergistically and promote healing potential of the combination of remedy. In support of the second explanation, reports indicate that the extracts of multiple of plant species may have an immunomodulatory effect, improving immune functions and some plant constituents may attenuate/reduce the side-effects of others (Ebong et al. 2008, Rasoanaivo et al. 2011, Tiwari \& Rao 2002). On the other hand, the use of a single species for a single ailment may be safer with less likelihood of side effects, and a single medicinal plant may contain tens of bioactive compounds that is potent enough to react against ailing agents. There are also reports from other cultures that similarly indicated use of single and multiple species remedy per human ailment, in North Ethiopia (Abebe \& Ayehu 1993, Beyene, 2015), in Zimbabwe (Maroyi 2011), Morocco (Ouhaddou et al. 2014), Nigeria (Ofuegbe \& Adedapo 2015), Peru (Luziatelli et al. 2010).

The predominant use of herbs for human ailments in our finding might be attributed to their wider distribution as early successional plants including from soil seed banks in human managed land uses and where forest cover has been depleted. Their ease for use is another attribute for their selection as remedy. However, their seasonality and damage by herbivore grazing makes them less sustainable. The fact that most medicinal species obtained from wild sources has might rise concern of conservation from overexploitation and poor management practices of the wild grown taxa (Awas 2007, Cunningham 2001, Castle et al. 2013). The distribution of Yem MPs in diverse habitats might have positive impact on their sustainability as well as accessibility. Especially, forests are the habitat predominantly used for obtaining remedies. This is attributed to that there are several community forests near villages of Yem people.

\section{Parts used and methods of preparation plant remedies}

The finding that leaf was the most used part might be with a thought that it contains healing bioactive substances, its ease for collection and its availability for most seasons of the year. Other studies similarly reported predominant use of leaf in other cultures (Beyene 2015, Bussmann \& Sharon 2006, Giday et al. 2009, Maroyi 2011). Maceration was the highest cited method of plant remedy preparation. By maceration method, the mixture of the damp solid plant material is pressed, then is strained, and the combined liquids are clarified by decantation or filtration after standing (Handa et al. 2008), There were no domestic studies which report maceration as a method of remedy preparation, albeit some studies from elsewhere similarly reported this method for remedy preparation in agreement with our finding (Eliseo 1983, Mowobi et al. 2016, Ouhaddou et al. 2014, Tugume \& Nyakoojo 2019.

\section{Paired Ranking, ICF, FL (\%) and DMR of medicinal species}

These tools showed that Yem area has high diversity of species that have popularity and cultural agreement among the communities. Hence, the species with highest values of these quantitative tools can be candidates for further phytochemical analyses and clinical trials for standardizing their employment in health system and development of drugs when possible. Rumex abyssinicus was the most preferred remedy for hepatitis. The Yem do not visit modern medical practitioners for this ailment, rather they use widely this species. The species is abundantly grown near homesteads that are well manured enset grounds as a weed, and rarely in forests in disturbed gaps. However, it is palatable for animals, which decimates its regeneration.

The highest ICF values obtained for gastrointestinal \& visceral organs ailments category indicates the highest prevalence of the ailments mentioned in this category. The high ICF score further indicates high dependence of local people on the plants that are available in the local flora, and its use for selection of specific plants for further search of bioactive compounds (Heinrich et al. 1998, 2009, Andrade-Cetto \& Heinrich 2011). The causes of high prevalence of ailments in this category might be attributed to poor hygienic living conditions such as absence of enough water for sanitation at home, drinking river water which might harbor some parasites, living along with domestic animals, feeding habits (for e.g., consuming uncooked foods such as raw meat, improper management of prepared foods, vectors such as flies, and lack of awareness, poor living conditions. According to Prüss-Üstün et al. (2008), the ailments associated with poor sanitation are particularly correlated with poverty which account for about $10 \%$ of the global burden of disease. In agreement with the current finding, there are other works that report prevalence of gastrointestinal diseases and internal organs disorders such as Garedew and Abebe (2018) in Yeki District Southwest Ethiopia, Bussmann and Sharon (2006) in northern Peru, Cheikhyoussef et al. (2011) in Namibia, Umair et al. (2017) in Hafizabad district, Punjab-Pakistan and Reimers et al. (2018) in Zacatecas state, Mexico.

The high-fidelity level values of species closer to $100 \%$ in this finding show that almost all use-mentions refer to the same purpose, that is, the plants are most preferred (Friedman et al. 1986). Generally, species with the highest 
fidelity level values are known to possess highest healing potential of ailments, and they are considered as model plants that can be employed for further phyotochemical investigation (Hassan-Abdallah 2013, Heinrich et al. 1998). The multipurpose MPs serve immense economic and sociocultural values and underpin the major ecosystem services. However, they are threatened by different livelihood activities such as agricultural expansion, extraction of fuel wood and charcoal, construction goods, and forage which violate their sustainable use. Therefore, it is important to monitor the impacts of such utility services, educate local communities on sustainable harvesting practices and cultivation of such species are some of the conservation measures suggested. Other studies also reported similar threats of multipurpose medicinal species (Adefa \& Getaneh 2013, Hunde et al. 2015, Tolassa 2007).

\section{Effects of socio-economic variables on $\mathbf{m p k}$}

The finding that gender was a significant predictor of mpk indicating that males were more knowledgeable than females in Yem might be attributed to difference in occupation. Yem males spend more times in farms that are closer to forests which contain more useful plant diversity and have much exposure for mpk while women work many times at home caring for children, preparing food, and localized near homesteads which might be less in plant species than forests. This occupation impact is cultural which cannot be changed easily and sooner. In agreement with our finding, there are other reports which indicted occupational difference in gender and dominance of males in mpk (Beyene 2015, Cheikhyoussef et al. 2011, Díaz-Reviriego et al. 2016, Fasil 2013, ReyesGarciaet al. 2010).

The significant difference in mpk among key and general informants, that the key informants knew more than the general informants might be attributed to specialization in herbal knowledge (Reyes-Garcia et al. 2010). Regassa (2016) similarly reported that medicinal experts could list more treatments than lay informants.

In our finding, religion was not a significant predictor mpk might be due to the fact the two faiths: the Christian and Muslim religions in Yem permit the use of medicinal plants to cure illnesses besides their belief in faith healing depending on doctrine of their religion. This agrees with reports from other cultures in Ethiopia by Beyene (2015) and Demie et al. (2018). The finding that age and education were not significant predictors of mpk might be attributed to that mpk is commonly a public domain which might be related the fact that the Yem have annual festival of gathering MPs by mass from Bori Mountain, in which all age groups and education groups participate and share mpk openly (Woldemariam in press). This finding disagrees with some studies reported that age as a of predictor of $\mathrm{mpk}$, and older people are more knowledgeable than the youngsters who distrust traditional medicine (Fasil 2013, Reyes-García et al. 2010). Our finding regarding education agrees with Birhanu et al. (2015) and MathezStiefel and Vandebroek (2012) who reported that mpk is not affected by level of education. The negative coefficients of gender, age, religion, and education in the regression equation suggest negative correlation; as the values of these variables increase, the mpk decreases, notwithstanding the later three were not significant predictors. The positive coefficient in informant proficiency indicates positive correlation and increase of mpk with informant proficiency.

The highest similarity of traditional MPs used in Yem with that of Sheko (Kassa et al. 2020), West Shoa Oromo (Regassa 2016), KembataTembaro (Maryo et al. 2015), Dawuro (Agize et al. 2013) and Goma Oromo (Etana et al. 2010) ethnic groups might be attributed similar climatic and topographic factors that dictate species grown and closer cultural proximity among the cultures in applying the available species for similar and different human ailments. The lesser similarity of MPs used in Yem with Gonder Amhara (Chekole 2017), Ankober Amhara (Lulekal et al. 2013) and Tigre (Kidane et al. 2017) might be due variation in species composition cultural variation in species preference. The least similarity of MPs used in Yem with Bale N. Park (Yineger et al. 2008), Harer Oromo (Belayneh \& Bussa 2014), Gera Oromo (Gonfa et al. 2020) and Berebere Bale Oromo (Tolossa \& Megersa 2018) might also be due to variation in species composition and cultural distance among them.

\section{Conclusion}

The study revealed that Yem people use a high diversity of MPs for treating human ailments, which indicates that they own deep-rooted traditional knowledge of managing human health care. For the Yem, MPs are accessible, efficacious, and entrusted natural means of primary health care. They treat most of the ailments first with MPs at home, if there would not be betterment, they visit either consult herbal experts, or biomedical health care depending on the type of ailment. They prefer traditional MPs for treating some ailments such as 'awachifebe'u', cancer, hepatitis, evil eye, 'mich' and sudden ailments among others thinking that the biomedical treatment is not effective against such ailments. Except for home garden grown cultivated species, the Yem collect MPs from any land use types from private lots as well as communal lands/forests, which are good reservoirs for medicinal and 
useful plants. Gender and proficiency were found to be predictors of mpk among the Yem in support of null hypotheses of the variables while the hypotheses for age, religion, and education as predictors of mpk in Yem were rejected. Conducting phytochemical screening and clinical trials of the MPs with high informant consensus and FL including Carduus schimperi, Haplocarpha rueppellii, Inula confortiflora, Maesa lanceolata and Rumex abyssinicus is suggested in the first priority line for their efficacy, safety and standard uses in primary health care. The Ethiopian Biodiversity Institute needs to work with local community for promoting and conserving the knowledge the biota and indigenous knowledge.

\section{Declarations}

List of abbreviations: Not applicable.

Ethics approval and consent to participate: A letter of cooperation for conducting the research was written on the behalf the corresponding author from Department of Plant Biology and Biodiversity Management, Addis Ababa University to Yem Special District Administration. The local authorities acknowledged the letter and gave permission to conduct the research, gather data from informants and field and take plant samples from field. Additionally, informants were asked about their view if their name is openly accessed, and they have agreed to have their names and personal data to be published. Then, Addis Ababa University approved the research finding after it was presented for the thesis defense.

Consent for publication: Not applicable.

Availability of data and materials: All the data are presented in figures, tables and appendix in the manuscript and are available with the corresponding author.

Competing interests: The authors declare that they have no competing interests.

Funding: Addis Ababa University, Ethiopia, financially supported the research.

Authors' contributions: Woldemariam collected, analyzed the data and written the manuscript, and was the major contributor of the study. Demissew and Asfaw advised, reviewed, and approved the final manuscript.

\section{Acknowledgements}

This paper is part of a PhD study that was hosted financially and materially supported by Addis Ababa University. We are grateful to Addis Ababa University. We are also thankful to the administration of Yem Special District, the late Mr. Kabtu W of Office of Culture Tourism and State Communication Affairs and subdistrict chairs and the informants for their cooperation and providing information for the study. We also thank guides Mr. Jorga W, Mr. Abawari A, and assistants Mr. Jemal M and Mr. Gisa M for their contribution to the study. We are also indebted to thank the anonymous reviewer for reading the manuscript and providing important comments.

\section{Literature Cited}

Abebe D, Ayehu A. 1993. Medicinal Plants and Enigmatic Health Practices of Northern Ethiopia, Berhanina Selam Printing Enterprise, Addis Ababa. Ethiopia,

Abebe E. 2011. Ethnobotanical study on medicinal plants used by local communities in Debark Wereda, North Gondar Zone, Amhara Regional State, Ethiopia. Msc Thesis. Addis Ababa University.

Adefa M, Getaneh S. 2013. Medicinal Plants Biodiversity and Local Health care Management System in Chencha District; GamoGofa, Ethiopia. Journal of Pharmacognosy and Phytochemistry 2:1.

Agize M, Demissew S, Asfaw Z. 2013. Ethnobotany of Medicinal Plants in Loma and Gena Bosa districts (Woredas) of Dawro Zone, Southern Ethiopia. Topclass Journal of Herbal Medicine 2(9):194-212.

Ahlberg BM. 2017. Integrated Health Care Systems and Indigenous Medicine: Reflections from the Sub-Sahara African Region. Frontiers of Sociology 2:12.

Andrade-Cetto A, Heinrich M. 2011. From the field into the lab: useful approaches to selecting species based on local knowledge: Mini Review Article. Frontiers in Pharmacology 2(20):1.

Awas T. 2007. Plant Diversity in Western Ethiopia: Ecology, Ethnobotany and Conservation. PhD thesis. Addis Ababa University.

Belayneh A, Busa N. 2014. Ethnomedicinal plants used to treat human ailments in the prehistoric place of Harla and Dengego valleys, eastern Ethiopia. Journal of Ethnobiology and Ethnomedicine 10:18. 
Beyene T. 2015. Ethnobotany of medicinal plants in Erob and Gulomeheda Districts, Eastern Zone of Tigray National Regional State, Ethiopia. PhD Dissertation. Addis Ababa University.

Birhanu T, Abera D, Ejeta E. 2015. Ethnobotanical Study of Medicinal Plants in Selected Horro Gudurru Woredas, Western Ethiopia. Journal of Biology, Agriculture and Health care 5:1.

Bussmann RW, Sharon D. 2006. Traditional medicinal plant use in Northern Peru: tracking two thousand years of healing culture. Journal of Ethnobiology and Ethnomedicine 2:47.

Cadena-González AL, Sørensen M, Theilade I. 2013. Use and valuation of native and introduced medicinal plant species in Campo Hermoso and Zetaquira, Boyacá, Colombia. Journal of Ethnobiology and Ethnomedicine 9:23.

Casagrande DG. 2002. Ecology, cognition, and cultural transmission of Tzeltal Maya medicinal plant knowledge. $\mathrm{PhD}$ Thesis. Athens, Georgia.

Castle LM, Leopold S, Craō R, Kindscher K. 2013. Ranking Tool Created for Medicinal plants at Risk of Being Overharvested in the Wild. Ethnobiology News Letters 5:77-88.

Cheikhyoussef A, Shapi M, Matengu K, Ashekele HM. 2011. Ethnobotanical study of indigenous knowledge on medicinal plant use by traditional healers in Oshikoto region, Namibia. Journal of Ethnobiology and Ethnomedicine 7:10.

Chekole G, Asfaw Z, Kelbessa E. 2015. Ethnobotanical study of medicinal plants in the environs of Tara-gedam and Amba remnant forests of Libo Kemkem District, northwest Ethiopia. Journal of Ethnobiology and Ethnomedicine 11:4.

Chekole G. 2017. Ethnobotanical study of medicinal plants used against human ailments in Gubalafto District, Northern Ethiopia. Journal of Ethnobiology and Ethnomedicine 13:55.

Cook FEM. 1995. Economic botany data collection standard. Prepared for the International Working Group on Taxonomic Databases for Plant Sciences (TDWG). Published by Kew: Royal Botanic Gardens.

CSA 2007. Central Statistical Authority (CSA). Census 2007 Tables: Southern Nations, Nationalities, and Peoples' Region. Archived November 2012, at the Wayback Machine. Tables 2.1 and 3.4.

Cunningham AB. 2001. Applied Ethnobotany. People Wild Plant Use and Conservation. London: Earthscan Publications Ltd.

Demie G, Negash M, Awas T. 2018. Ethnobotanical study of medicinal plants used by indigenous people in and around Dirre Sheikh Hussein heritage site of south-eastern Ethiopia. Journal of Ethnopharmacology 220(28):87-89.

Deribe K, Amberbir A, Getachew B, Mussema Y. 2006. A historical overview of traditional medicine practices and policy in Ethiopia. Ethiopian Journal of Health Development 20:127-134,

Desmarchelier C, Witting-Schaus F. 2000. Sixty Medical Plants from Peruvian Amazon. Ecology, Ethnomedicine and Bioactivity. Lima, Peru, PROTERRA Ed.

Díaz-Reviriego I, Ferna'ndez-Llamazares A, Salpeteur M, Howard PL, Reyes-García V. 2016. Gendered medicinal plant knowledge contributions to adaptive capacity and health sovereignty in Amazonia. Ambio 45(Suppl. 3):S263S275.

Ebong PE, Atangwho IJ, Eyong EU, Egbung GE. 2008. The Antidiabetic Efficacy of Combined Extracts from Two Continental Plants: Azadirachta indica (A. Juss) (Neem) and Vernonia amygdalina (Del.) (African Bitter Leaf). American Journal of Biochemistry and Biotechnology 4(3):239-244.

Etana B. 2010. Ethnobotanical Study of Traditional Medicinal Plants of Goma Wereda, Jima Zone of Oromia Region, Ethiopia. MSc Thesis. Addis Ababa University.

Fabricant DS, Farnsworth NR. 2001. The value of plants used in traditional medicine for drug discovery. Environmental Health Perspectives 109 (Suppl 1): 69-75.

FAO 2010. Food and Agriculture Organization of the United Nations (FAO). The State of Food Insecurity in the World. Rome.

Farnsworth NR, Soejarto DD. 1991. Global importance of medicinal plants. In The Conservation of Medicinal Plants, Edited by Akerele O, Heywood V \& Synge H. Cambridge University Press, UK, Pp 25-51. 
Fasil H. 2005. Beyond Plants, Professionals \& Parchments: The role of home-based medicinal plant use and traditional health knowledge in primary health care in Ethiopia. Ethnobotany Research \& Applications 3:37-49.

Friedman J, Yaniv Z, Dafni A, Palewitch DA. 1986. Preliminary classification of the healing potential of medicinal plants, based on a rational analysis of an ethnopharmacological field survey among Bedouins in the Negev Desert, Israel. Journal of Ethnopharmacology 16(2-3):275-287.

Kent M, Cocker. 1992. Vegetation Description and Analysis: A Practical Approach. Belhaven press, London, UK.

Garedew B, Abebe D. 2018. Ethnomedicinal plants used for the treatment of gastro-intestinal parasitic diseases in human in Yeki district, Southwest Ethiopia. African Journal of Pharmacy and Pharmacology 12(22):298-309.

Giday M, Asfaw Z, Woldu Z. 2009. Medicinal plant knowledge of the Bench ethnic of Ethiopia: an ethnobotanical investigation. Journal of Ethnobiology and Ethnomedicine 5:34.

Giday M. 2007. Medicinal plants of Bench, Meinit and Sheko sociocultural groups in Ethiopia with on diversity, distribution, and abundance. PhD Thesis. Addis Ababa University.

Gonfa N, Tulu D, Hundera K, Raga D. 2020. Ethnobotanical study of medicinal plants, its utilization, and conservation by indigenous people of Gera district, Ethiopia. Cogent Food \& Agriculture 6:1852716.

Handa SS, Khanuja SPS, Longo G, Rakesh DD. 2008. Extraction technologies for medicinal and aromatic plants, Trieste: ICS UNIDO.

Hassan N, Wang D, Zhong Z, Nisar M, Zhu Y. 2017. Determination and analysis of informant consensus factor of medicinal plant species used as remedy in Northern Pakistan. Journal of Biodiversity and Environmental Sciences 11:117-133.

Hassan-Abdallah A, Merito A, Hassan S, Aboubaker D, Djama M, Asfaw Z, Kelbessa E. 2013. Medicinal plants and their uses by the people in the region of Randa, Djibouti. Journal of Ethnopharmacology 148(2):8701-13.

Hedgerg I, Friis I, Persson E 2009. General Part and Index to V 1-7. Flora of Ethiopia and Eritrea vol. 8, The National Herbarium (ETH), Biology Department, Addis Ababa, Ethiopia \& Department of Systematic Botany, Uppsala, Sweden.

Heinrich M, Ankil A, Frei B, Weimann C, Sticher O. 1998. Medicinal plants in Mexico; Healers, Consensus and Cultural importance. Social Science Medicine 47(11):1859-7181.

Heinrich M, Edwards S, Moerman DA, Leonti M. 2009. Ethnopharmacological field studies: a critical assessment of their conceptual basis and methods. Journal of Ethnopharmacology 124:1-17.

Hong L, Guo Z, Huang K, Wei S, Liu B, Meng S, Long C. 2015. Ethnobotanical study on medicinal plants used by Maonan people in China. Jounal of Ethnobiology and Ethnomedicine 11:32.

Hunde D, Amdeta C, Birhanu T, Sharma M. 2015. Medicinal plants use and conservation practice in Jimma Zone, South-West Ethiopia. International Journal of Biodiversity and Conservation 7(3):202-210.

IBM 2011. IBM Corp. Statistical Package for Social Science (SPSS), Statistics for Windows, Version 20.0, Armonk, NY.

Kassa Z, Asfaw Z, Demissew S. 2020. An ethnobotanical study of medicinal plants in Sheka Zone of Southern Nations Nationalities and Peoples Regional State, Ethiopia. Journal of Ethnobiology and Ethnomedicine 16:7.

Kidane L, Gebremedhin G, Beyene T. 2018. Ethnobotanical study of medicinal plants in Ganta Afeshum District, Eastern Zone of Tigray, Northern Ethiopia. Journal of Ethnobiology and Ethnomedicine 14:64.

Levine DN. 1974. Greater Ethiopia: The Evolution of a Multi-Ethnic Society. University of Chicago Press, Chicago.

Lulekal E, Asfaw Z, Kelbessa E, Van Damme P. 2013. Ethnomedicinal study of plants used for human ailments in Ankober District, North Shewa Zone, Amhara Region, Ethiopia. Journal of Ethnobiology and Ethnomedicine 9:63.

Lulekal E, Kelbessa E, Bekele T, Yineger H. 2008. An ethnobotanical study of medicinal plants in Mana Angetu District, southeastern Ethiopia. Jounal of Ethnobioogy and Ethnomedicine 4:10.

Luziatelli G, Sørensen M, Theilade I, Mølgaard P. 2010. Asháninka medicinal plants: a case study from the native community of Bajo Quimiriki, Junín, Peru. Journal of Ethnobiology and Ethnomedicine 6:21. 
Maroyi A. 2011. An ethnobotanical survey of medicinal plants used by the people in Nhema communal area, Zimbabwe. Journal of Ethnopharmacololgy 136(2):347-54.

Martin GJ. 1995. Ethnobotany: A Methods Manual. People and Plants Conservation, Springer.

Maryo M, Nemomisa S, Bekele T. 2015. An ethnobotanical study of medicinal plants of the Kembatta ethnic group in Enset-based agricultural landscape of Kembatta Tembaro (KT) Zone, Southern Ethiopia. Asian Journal of Plant Science and Research 5(7):42-61.

Mathez-Stiefel S-L, Vandebroek I. 2012. Distribution and Transmission of Medicinal Plant Knowledge in the Andean Highlands: A Case Study from Peru and Bolivia. Evidence-Based Complementary and Alternative Medicine Article ID 959285 .

Moerman D, Robert E, Pemberton W, Kiefer D, Berlin B. 1999. A comparative analysis of five medicinal floras. Journal of Elhnobiology 19(1):49.-67.

Mowobi GG, Abubakar S, Charles O, Etim, VN, Ogech N, Egya JJ. 2016. Ethnobotanical Survey of Medicinal Plants Used for the Treatment of Skin Disease in Keffi, Nigeria. American Journal of Phytomedicine and Clinical Therapeutics 4(2):2073-090.

Negash M (Ambassador) 2005. Legal system of Yem /'Yeyem higsireat'. Chamber Printing Press. (Mimeographed, in Amharic).

NMSA 2014. National Metrological Services Agency. Metrological Data of Yem, at Deri Station 2000-2012. Addis Ababa.

Ofuegbe SO, Adedapo AA. 2015. Ethnomedicinal survey of some plants used for the treatment of diabetes in Ibadan, Nigeria. Asian Journal of Medical Sciences 6:5.

Ouhaddou H, Boubaker H, Msanda F, El Mousadik A. 2014. An Ethnobotanical Study of Medicinal Plants of the Agadir Ida Ou Tanane Province (Southwest Morocco). Journal of Applied Biosciences 84 :7707-7722.

Pankhurst R. 2001. The Status and Availability of Written and Oral Knowledge on Traditional Health Care in Ethiopia. In Conservation and Sustainable Use of Medicinal Plants in Ethiopia. Edited by Zewdu M \& Demissie A. Proceedings of the National Workshop on Biodiversity Conservation and Sustainable Use of Medicinal Plants in Ethiopia, Institute of Biodiversity Conservation and Research, Addis Ababa, Ethiopia, Pp. 1-21.

Prüss-Üstün A, Bos R, Gore F, Bartram J. 2008. Safer water, better health: costs, benefits, and sustainability of interventions to protect and promote health. World Health Organization, Geneva.

Rasoanaivo P, Wright CW, Willcox ML, Gilbert B. 2011. Whole plant extracts versus single compounds for the treatment of malaria: synergy and positive interactions. Malaria Journal 10(Suppl 1):S4.

Regassa T. 2016. Vascular Plant Diversity and Ethnobotanical Study of Medicinal and Wild Edible Plants in Jibat, Gedo and Chilimo Forests, West Shewa Zone of Oromia Region, Ethiopia. PhD Dissertation. Addis Ababa University.

Reimers EAL, Cusimamani EF, Rodríguez EAL, Valle JMZ, Polesny Z, Pawera L. 2018. An ethnobotanical study of medicinal plants used in Zacatecas state, Mexico. Acta Societatis Botanicorum Poloniae 87(2):35-81.

Reyes-García V, Kightley E, Ruiz-Malle'n I, Fuentes-Pela'ez N, Demps K, Tomas N, Martínez-Rodríguez R. 2010. Schooling and local environmental knowledge: Do they complement or substitute each other? International Journal of Educational Development 30(3):305-313.

Sílvia MF, João B, Barreira CM, Beatriz M, Oliveira PP. 2015. Asteraceae species with most prominent bioactivity and their potential applications: A review. Industrial Crops and Products 76:604-615.

Sofowora A, Ogunbodede E, Onayade A. 2013. The role and place of medicinal plants in the strategies for disease prevention. African Journal of Traditional, Complement \& Alternative Medicine 10(5):210-229

Tadesse M, Demissew S. 1992. Medicinal Ethiopian plants: inventory, identification, and classification. In Plants used in African traditional medicine as practiced in Ethiopia and Uganda, Edited by Edwards S \& Asfaw Z. Botany 2000: East and Central Africa: NAPRECA Monographs Series No. 5. NAPRECA, Addis Ababa University, Addis Ababa, Pp. 1-19. 
Tiwari AK, Rao JM. 2002. Diabetes mellitus and multiple therapeutic approaches of phytochemicals: Present status and future prospects. Current Science 83(1):30-37.

Tolassa E. 2007. Use and management of medicinal plants in Ghimbi District, Southwest Ethiopia. MSc thesis, Addis Ababa University.

Tolossa T, Megersa M. 2018. Ethnobotanical Study of Medicinal Plants Used to Treat Human Diseases in Berbere District, Bale Zone of Oromia Regional State, South-East Ethiopia. Evidence-Based Complementary and Alternative Medicine 2018: 8602945.

Trotter RT, Logan MH. 1986. Informant Consensus: a new approach for identifying effective medicinal plants. In Plants in Indigenous Medicine and Diet. Edited by Etkin NL Bedford Hill: Redgrave Publishing Company, New York, Pp. 91-112,

Umair M, Altaf M, Abbasi AM. 2017. An ethnobotanical survey of indigenous medicinal plants in Hafizabad district, Punjab-Pakistan. PLOSOnehttps://doi.org/10.1371/journal.pone.0177912.

UNESCO 2015. United Nations Education, Science and Culture Organization (UNESCO). Country Programming Document, Addis Ababa, Ethiopia.

WHO 2002. World Health Organisation (WHO), Traditional medicine strategy, 2002-2005, Geneva.

YDAO 2016.Yem District Agricultural Office (YDAO). District Report on Natural resources. Saja.

Yineger H, Kelbessa E, Bekele T, Lulekal E. 2008. Plants used in traditional management of human ailments at Bale Mountains National Park, Southeastern Ethiopia. Journal of Medicinal Plants Research 2:132-153. 